\title{
USO DO SIG PARA O CADASTRO DO PATRIMÔNIO URBANO: 0 QUADRILÁTERO CENTRAL DE RIBEIRÃO PRETO (SP)
} USE OF GIS FOR THE REGISTRATION OF THE URBAN HERITAGE: THE QUADRILÁTE
CENTRAL IN RIBEIRÃO PRETO (SP)

\author{
Ana Teresa Cirigliano Villela ${ }^{1}$, Gustavo Nogueira Zeoti ${ }^{2}$
}

\section{RESUMO:}

Este artigo objetiva apresentar a sistemática de cadastro de edificações de interesse histórico do Quadrilátero Central de Ribeirão Preto (SP) por meio de Sistema de Informação Geográfica (SIG), com destaque para a inclusão das arquiteturas menores. $O$ interesse pela preservação destas arquiteturas remonta ao ambiente italiano do final do século XIX, quando se discutiam as estratégias de proteção das ambiências pitorescas. Ganhou relevância com a Carta de Veneza, em 1964, que considerou como monumentos históricos não apenas as criações arquitetônicas grandiosas e isoladas, como também as obras modestas. No Quadrilátero Central, onde teve início a ocupação urbana, está concentrada a maior parte do patrimônio cultural tombado do município. Dentre as edificações tombadas, são marcantes as características monumentais, associadas ao café e a personagens da elite local, contrapondo-se às características singelas das arquiteturas de caráter menor. Ambas caracterizam a área como uma paisagem histórica urbana, essencialmente heterogênea, cuja preservação demanda estudos e cadastros sistemáticos. Com o objetivo de documentar e oferecer subsídios para sua preservação, entre 2016 e 2019, foi desenvolvido o projeto "Levantamento histórico-patrimonial do Quadrilátero Central de Ribeirão Preto (SP)". Em 2019, nesse projeto adotou-se um SIG, que possibilitou o armazenamento, a espacialização, a classificação e o processamento de grande volume de dados das edificações de interesse histórico remanescentes na paisagem. A criação desse sistema abre possibilidade de aplicação a outros recortes territoriais, tanto do próprio município quanto de outros, bem como do delineamento de estratégias de preservação a partir de parcerias entre administração pública e universidades.

PALAVRAS-CHAVE: Inventário; Preservação de Bens Culturais; Patrimônio Cultural.

\section{ABSTRACT:}

This article aims to present the systematic registration of buildings of historical interest in the Quadrilátero Central of Ribeirão Preto (SP) using Geographic Information System (GIS), with emphasis on the inclusion of the minor architecture. The interest in preserving this kind of architecture goes back to the Italian environment of the late 19th century, when the strategies for protecting picturesque environments were discussed. It gained relevance with the Venice Charter in 1964, which considered not only grandiose and isolated architectural creations, but also modest works as historical monuments. The Quadrilátero Central, where the urban occupation began, concentrates most of the cultural heritage listed in the county. Among the listed buildings, monumental characteristics, associated with the coffee period and the characters of the local elite, opposed to the simple characteristics of the minor architectures. Both characterize the area as an historical urban landscape, essentially heterogeneous, whose preservation requires systematic studies and records. With the objective of documenting and offering subsidies for ITS preservation, between 2016 and 2019, the project "Historical and patrimonial survey of the Quadrilátero Central of Ribeirão Preto (SP)" was developed. In 2019, this project adopted a GIS, which enabled the storage, spatialization, classification and processing of a large volume of data about buildings of historical interest remaining in the landscape. The creation of this system opens possibility of application to other areas, both from the municipality itself and from others, as well as from the design of preservation strategies based on partnerships between the public administration and universities.

KEYWORDS: Inventory; Cultural Heritage Preservation; Cultural Heritage.

How to cite this article:

VILLELA, A. T. C.; ZEOTI, G. N. Uso do SIG para o cadastro do patrimônio urbano: o Quadrilátero Central Ribeirão Preto (SP). Gestão \& Tecnologia de Projetos. São Carlos, v16, n3, 2021. https://doi.org/10.11606/gtp.v16i3.171819
Fonte de Financiamento: Declara não haver.

Conflito de Interesse:

Declara não haver.

Ética em Pesquisa:

Declara não haver necessidade.

Submetido em: 30/06/2020 Aceito em: 03/04/2021 


\section{INTRODUÇÃO}

Este artigo objetiva apresentar a sistemática de cadastro de edificações de interesse histórico do Quadrilátero Centrali de Ribeirão Preto (SP), por meio de Sistema de Informação Geográfica (SIG). Por cadastro, entende-se o conjunto de dados relativo a cada uma das edificações identificadas em campo e avaliadas como de interesse histórico. Já os Sistemas de Informação Geográfica (SIG) são "[...] sistemas computacionais utilizados para armazenar e manipular informações geográficas [...]" (ARONOFF, 1991, p. 1, tradução nossa). O uso de SIG é amplamente difundido na área do Planejamento Urbano e, desde a década de 1990, vem sendo direcionado também a pesquisas históricasii, pois viabilizam "[...] a elaboração de cartografias regressivas e temáticas [...], cruzando informações textuais e visuais, reconstituindo perfis tanto materiais como sociais nos diversos tempos [...]" (BUENO, 2016, p. 442).

0 uso de tecnologias digitais aplicadas à documentação do Patrimônio Cultural tem sido disseminado nos últimos anos para atender às demandas de salvaguarda do rol de bens materiais e imateriais que integram o corpus patrimonial das sociedades contemporâneas. No caso do patrimônio urbano, foram incorporados às teorias e políticas de preservação patrimonial novos valores, escalas, tipologias e recortes cronológicos, demandando, assim, novas estratégias de conservação e gestão.

Segundo Choay (2006), o alargamento da noção de patrimônio se iniciou na década de 1960. A Carta de Veneza de 1964 se tornou, desde então, o documento internacional basilar para esse novo entendimento e para o direcionamento de estratégias de gestão, conservação e restauro dos então chamados monumentos históricos. Os monumentos históricos passaram a ser entendidos não só como grandes criações isoladas, mas também como obras modestas que tenham adquirido significação cultural (ICOMOS, 1964).

No entanto, desde o final do século XIX, as Associações Artísticas Italianas já faziam referência à necessidade de reconhecimento e catalogação das obras modestas e da preservação das ambiências pitorescas (CABRAL, 2013). Foi no âmbito dessas e de outras associações de salvaguarda da paisagem europeia iii, ligadas aos primeiros movimentos ecológicos, que se difundiu o interesse pela preservação da memória e pelo restauro das chamadas arquiteturas menores, especialmente das rurais (TOSCO, 2017). Essas questões foram incorporadas às primeiras legislações europeias, para as quais muito contribuiu o italiano Gustavo Giovannoni.

"Arquiteturas menores" é uma expressão utilizada “[...] para designar construções privadas não monumentais, em geral edificadas sem a cooperação de arquitetos [...]" (CHOAY, 2006, p. 12). Durante sua atuação multifacetada no cenário cultural italiano, obscurantizado pelo regime fascista, Giovannoni foi um dos primeiros a teorizar sobre a importância das arquiteturas menores na constituição da paisagem histórica. Ressaltava o seu valor "[...] tanto em razão de seu caráter coletivo ou de suas relações com edifícios mais grandiosos, quanto pelos testemunhos que elas nos trazem da arquitetura corrente de diversas épocas [...]" (GIOVANNONI, 2013, p. 181).

Também foi fundamental para a ampliação da noção de monumento histórico a contribuição do historiador e crítico de arte austríaco Alois Riegl. Em "O Culto Moderno dos Monumentos", publicado em 1903, estabeleceu parâmetros de preservação dos edifícios e obras de arte baseados em valores diretamente relacionados à vontade artística de cada época (RIEGL, 2014). Se no século XIX esses valores se restringiam ao legado da Antiguidade Clássica e da Idade Média, ao final do século XX eles passariam a incidir também sobre edifícios do movimento moderno, industriais e ferroviários (CHOAY, 2006). Embora Riegl não tenha incorporado as arquiteturas menores ao seu discurso, a questão das ressignificações histórico- 
culturais dos edifícios e obras de arte foi finalmente chancelada na definição de monumentos históricos apresentada na Carta de Veneza.

Sob o ponto de vista metodológico, Saverio Muratori e seus ex-alunos e assistentes, Gianfranco Caniggia e Gian Luigi Maffei, ofereceram possibilidades sistemáticas de leitura e análise das arquiteturas menores, por ele chamadas de "edificações de base" (CANIGGIA; MAFFEI, 1995). Muratori colocou em xeque o próprio ensino de arquitetura italiano, até então pautado por uma erudição da prática arquitetônica em oposição às construções populares.

É evidente que nossas cidades não estão condicionadas pelas poucas obras aceitas como "arquitetura", mas sim pelas muitíssimas condenadas ao anonimato da edificação, cuja história e cujo devir são desdenhados pelos muitos cultivadores da "história da arquitetura", sujeitos às mesmas condicionantes que fazem agora do ensino de história, em geral, a história dos personagens, dos eventos, das guerras, desconsiderando a maioria da humanidade que, mesmo sendo vítima e campo de atuação dos personagens, eventos e guerras, é a autêntica protagonista da história do homem em sua variada e contínua produção do próprio ambiente; é a história da humanidade o que mais nos interessa, essa história que começa a aparecer, já não tão esporadicamente, nos estudos especializados de história econômica e história social (CANIGGIA; MAFFEI, 1995, p. 13, tradução nossa).

Tal perspectiva é muito semelhante àquela dos historiadores dos Annales, que se dedicaram ao projeto de inversão do sentido da história (BURKE, 1992). Enquanto Muratori e seus exalunos reclamavam o papel das edificações comuns na historiografia da arquitetura, Marc Bloch, Lucien Febvre e Fernand Braudel buscavam na coletividade as bases para uma nova historiografia que superasse o viés dos grandes acontecimentos e dos personagens heroicos

0 estudo das arquiteturas menores, ou edificações de base, raramente dispõe de documentos sistematizados ou bibliografia específica. Ao contrário,

A arquitetura urbana é quase sempre anônima, tributária de tipos transmitidos por 'vizinhança' que dependem dos saberes tradicionais dos empreiteiros e artesãos, do respeito a uma regulamentação simples e do consenso que se estabeleceu quanto a usos correntes: alinhamentos, paredes geminadas, disposição de pátios, etc. (PANERAI, 2006, p. 117).

Pesquisar as edificações ditas anônimas exige, pois, a investigação de múltiplas fontes, tais como impostos prediais, processos litigiosos, permissões para construção, livros de entrada de projetos, propagandas em jornais e almanaques, décimas urbanas, licenças de construção, anuários estatísticos, projetos, fotografias, dentre outros. Há ainda uma fonte em potencial representada pela própria matéria edificada, que é, inclusive, a característica que distingue o objeto arquitetônico do objeto da historiografia geral (WAISMAN, 2013).

0 reconhecimento da matéria edificada como documento histórico possibilita a transcendência de padrões eurocêntricos de classificação e periodização, que durante décadas protagonizaram as narrativas historiográficas do Brasil e de toda América Latina. Classificações essas nem sempre aplicáveis às arquiteturas menores, uma vez que elas se desenvolvem às margens da produção oficial e dos estilos de moda. Mesmo no caso das edificações "oficiais", projetadas na transição do século XIX para o XX por profissionais diplomados em engenharia e arquitetura, há certa imprecisão nas análises estilísticas. Ao invés de estilos, edificações latino-americanas foram baseadas em ideias transculturais, "[...] interpretadas, modificadas ou transformadas de acordo com circunstâncias histórico-cultural-tecnológicas locais [...]” (WAISMAN, 2013, p. 59). 
Ainda que os estudos de Giovannoni e Muratori tenham se baseado em casos italianos, que somam séculos de estratificações históricas, com largas acumulações de tradições construtivas, o reconhecimento tipológico das edificações desenvolvido por Muratori abre possibilidades para se estudar as arquiteturas menores brasileiras. São, portanto, fundamentais estudos sistemáticos dessa produção, que hoje contam com tecnologias como o SIG.

\section{A NOÇÃO DE PATRIMÔNIO URBANO NO BRASIL}

No Brasil, de acordo com Weimer (2005), a arquitetura popular não costuma fazer parte do imaginário dos arquitetos. $\mathrm{O}$ autor ressalta que à época da criação do Serviço do Patrimônio Histórico e Artístico Nacional (SPHAN), havia significativos trabalhos conduzidos por Gilberto Freyre, Lúcio Costa e Mário Andrade que contemplavam o fazer popular - a exemplo dos estudos sobre os mocambos recifenses e os mestres pedreiros portugueses, além das viagens exploratórias que objetivavam inventariar as mais diversas manifestações artísticas brasileiras. No entanto, a instituição mudou de orientação, passando a privilegiar o estudo e a tutela de edificações monumentais enquanto eventuais obras de caráter popular foram travestidas de eruditas, como o caso típico da arquitetura colonial mineiraiv (WEIMER, 2005).

O patrimônio histórico e artístico oficialmente eleito pelo então SPHAN era constituído por edifícios e alguns sítios coloniais, considerados representações genuínas do "abrasileiramento" de técnicas construtivas portuguesas.

O conjunto eleito revela o desejo por um país passado, com quatro séculos de história, extremamente católico, guardado por canhões, patriarcal, latifundiário, ordenado por intendências e casas de câmara e cadeia, e habitado por personagens ilustres, que caminham entre pontes e chafarizes. (RUBINO, 1996, p. 98).

Durante a ditadura militar, emergiram novos discursos sociais e políticos, nos quais reclamavase o reconhecimento da diversidade cultural brasileira ao mesmo tempo em que se reivindicava o desejo de um país livre. Instaurou-se um “[...] um espaço possível de organização social [...] que fez surgir uma demanda não institucional para a preservação de imóveis e sítios urbanos [...]" (MOTTA, 2000, p. 16). Tais discursos, somados aos princípios da Carta de Veneza, foram incorporados à Constituição da República Federativa do Brasil, de 1988. Desde então, o patrimônio cultural brasileiro passou a ser definido como o conjunto de "[...] bens de natureza material e imaterial, tomados individualmente ou em conjunto, portadores de referência à identidade, à ação, à memória dos diferentes grupos formadores da sociedade brasileira [...]" (BRASIL, 2020, p. 114). Implicitamente, as arquiteturas menores estão inseridas nos conjuntos apontados pelo referido artigo. Trata-se de um reconhecimento recente que justifica, ainda que parcialmente, o fato de, na prática, o patrimônio nacional, estadual e municipal ainda ser constituído, em maioria, por edificações isoladas e de excepcional valor artístico, arquitetônico e histórico, ligadas às classes dominantes.

$\mathrm{Na}$ Europa, os debates acerca da conservação de grandes áreas urbanas de valor histórico, ao invés de edifícios isolados, vem ganhando protagonismo desde o final da Segunda Guerra Mundial, quando tiveram início as reconstruções de cidades ${ }^{v}$ destruídas pelos bombardeios (MOTTA, 2000). É merecedora de destaque a Declaração de Amsterdã, redigida em 1975 pelo Conselho da Europa, como síntese desses debates e como base para o delineamento de políticas de conservação integradas ao desenvolvimento urbano e econômico (CONSELHO DA EUROPA, 1975). Contudo, a declaração teve um alcance restrito aos países europeus. Em cidades latinoamericanas, as destruições de edificações, conjuntos e bairros históricos encontram dentre 
suas causas o rápido e contínuo processo de mudanças urbanas, que age contra a consolidação da imagem urbana e, consequentemente, da memória social (WAISMAN, 2013).

Estratégias internacionais em prol da conservação do patrimônio urbano, em complementação aos princípios da Carta de Veneza, foram apresentadas pela Organização das Nações Unidas para a Educação, a Ciência e a Cultura (Unesco) somente em 2011. 0 documento chamado de "Recomendação sobre a Paisagem Histórica Urbana" reforçou a importância da capacitação das comunidades, decisores, profissionais e gestores, bem como da documentação e compreensão das complexas estratificações das áreas urbanas e dos seus componentes constitutivos, para equilibrar a conservação de seu caráter histórico com as demandas da urbanização contemporânea (UNESCO, 2011).

Além das diretrizes, a recomendação apresentou o conceito de paisagem histórica urbana como a "[...] área urbana que resulta da estratificação histórica de valores e atributos culturais e naturais, que transcende a noção de 'centro histórico' ou de 'conjunto histórico' para incluir o contexto urbano mais abrangente e a sua envolvente geográfica." (UNESCO, 2011, p. 4). A mudança da ênfase primária sobre os monumentos arquitetônicos isolados para um contexto mais abrangentevi implicou na adaptação das políticas existentes e na criação de novos instrumentos para documentar, compreender e apresentar a paisagem urbana (UNESCO, 2011).

A leitura da paisagem urbana histórica é, portanto, um processo complexo, sobretudo quando tem por finalidade subsidiar ações de conservação, que se sobrepõem a uma série de outras demandas do planejamento urbano (UNESCO, 2011). Por isso, a Unesco incentiva o uso de tecnologias da informação e comunicação, dentre as quais "[...] o uso de ferramentas GIS é enfatizado [...] pelo seu emprego em áreas que demandam análise espacial, representação e visualização das estruturas ambientais urbanas [...]" (ARRUDA; AMORIM, 2010, p. 399).

Neste artigo, serão apresentados os resultados do SIG histórico do Quadrilátero Central de Ribeirão Preto, que foi concebido no âmbito do projeto de documentação "Levantamento histórico-patrimonial do Quadrilátero Central de Ribeirão Preto (SP)" e hoje faz parte da tese "Arqueologia da Paisagem Urbana: o processo de (trans)formação do Quadrilátero Central de Ribeirão Preto (SP)", em andamento no Instituto de Arquitetura e Urbanismo da Universidade de São Paulo, sob orientação da Prof. Dra. Maria Angela Bortolucci.

\section{O PATRIMÔNIO URBANO DE RIBEIRÃO PRETO (SP): O CASO DO QUADRILÁTERO CENTRAL}

O município de Ribeirão Preto está situado no nordeste do Estado de São Paulo e ficou conhecido a partir do final do século XIX pelas suas férteis terras para o cultivo do café, posteriormente substituído pela cana de açúcar. A ocupação da região teve início em meados do século XIX e, a partir de 1870, desenvolveu-se em paralelo à economia cafeeira, que entrou em decadência na década de 1940. 0 que hoje se reconhece como "paisagem cultural do café" compreende a herança desse período.

No entanto, não há chancela oficial da paisagem cultural do café em Ribeirão Preto. Há apenas o tombamento de remanescentes da antiga Fazenda Monte Alegre, onde atualmente funciona o campus da Universidade de São Paulo, de algumas estações ferroviárias da Companhia Mogiana e, principalmente, de edificações urbanas dotadas de excepcional valor artístico e arquitetônico e vinculadas a personagens notórios, como políticos e ou fazendeiros atuantes na região.

$51 \%$ dos bens tombados no município estão localizados no Quadrilátero Central, onde teve início a ocupação urbana. 0 primeiro edifício reconhecido pelo seu valor histórico e artístico 
foi o Theatro Pedro II, em 1973. 0 tombamento foi efetivado em 1982 pelo CONDEPHAAT e em 1985 pelo município, dentro do conjunto denominado Quarteirão Paulista. A ele, seguiram os tombamentos de prédios eclesiásticos, sedes dos poderes executivo e legislativo, hotéis da antiga burguesia, palacetes dos antigos fazendeiros e outros edifícios grandiosos que materializam na paisagem urbana a pujança econômica relacionada ao café (Figura 1).

Nesse contexto, a tutela das arquiteturas menores fica circunscrita às áreas envoltórias, quando definidas, com exceção para o conjunto edificado à Rua José Bonifácio, sob tombamento provisório desde 2008.

\section{Figura 1. Antiga residência de Sinhá Junqueira, hoje biblioteca, e Theatro Pedro II, ambas edificações tombadas no município de Ribeirão Preto. \\ Fonte: Fotos de Gustavo Zeoti, 2020.}

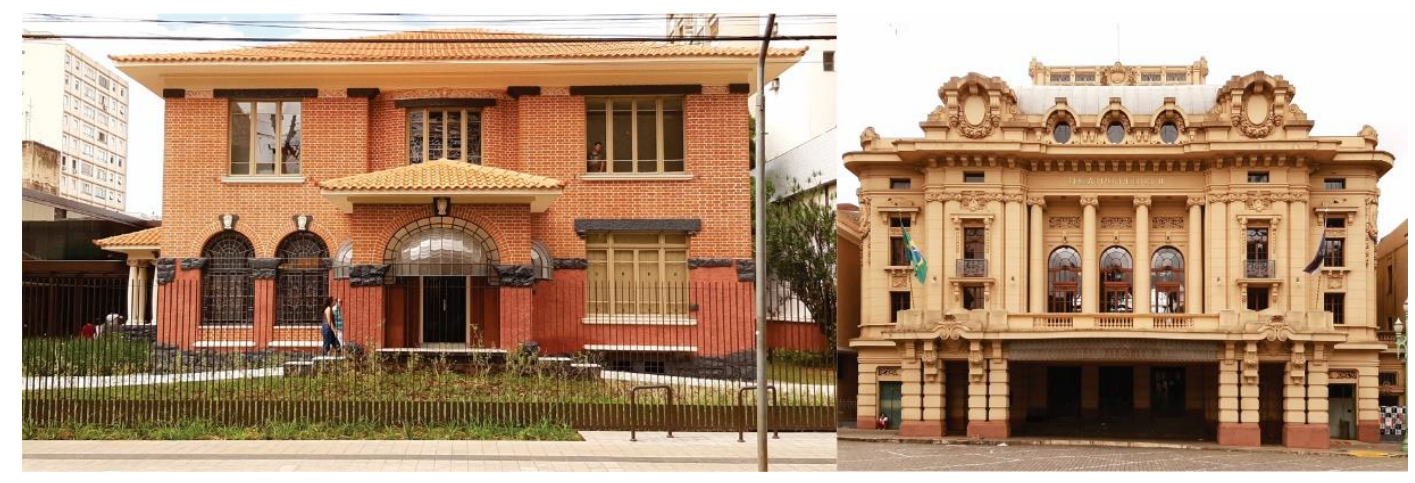

A despeito das demolições, do abandono e da descaracterização que muitas edificações, inclusive aquelas tombadas, vêm sofrendo no Quadrilátero Central, ainda remanescem muitas tipologias históricas reconhecíveis e que compõem um conjunto urbano de inestimável valor cultural. Por outro lado, as políticas de preservação são fragmentárias e limitadas aos tombamentos de edifícios isolados e grandiosos.

Com o objetivo de documentar e oferecer subsídios para a preservação do Quadrilátero Central, entre 2016 e 2019, foi desenvolvido o projeto de documentação "Levantamento histórico-patrimonial do Quadrilátero Central de Ribeirão Preto (SP)". 0 projeto foi realizado em duas fases. A primeira foi desenvolvida dentre 2016 e 2018, no âmbito do Escritório Modelo de um Curso de Arquitetura e Urbanismo, sob coordenação dos então docentes Ana Teresa Cirigliano Villela e Marcelo Carlucci. Em 2019, o projeto foi reformatado como atividade de extensão. Nessa segunda fase, contou-se com a colaboração do arquiteto e urbanista pesquisador Gustavo Nogueira Zeoti e a participação das alunas de graduação Leticia Fiacadori, Livia Amorim, Tainah dos Reis, Talita de Oliveira e Vanessa Laredo.

A princípio, tratava-se de uma proposta pedagógica que tinha como objetivo direcionar o olhar dos alunos para a produção arquitetônica dita menor, especificamente aquela circunscrita ao Quadrilátero Central. Na ocasião, poucos eram os alunos do curso que, de fato, conheciam ou frequentavam a área. Especificamente na disciplina de Técnicas Retrospectivas e em Trabalhos Finais de Graduação que tratavam da temática patrimonial, percebeu-se ainda a predileção dos estudantes por monumentos tombados e ou dotados de características arquitetônicas pujantes. Dentre as razões para essa predileção estaria a maior facilidade de se ter acesso a dossiês de tombamento e pesquisas anteriores com informações acerca desses bens, ainda que escassas. Ou seja, os edifícios em si não eram estudados como documentos informativos.

Seria essa predileção por edificações monumentais uma consequência do alinhamento ao conteúdo das disciplinas do eixo de Teoria e História, igualmente previstos como uma cronologia de obras e arquitetos notórios? Ou seria um reflexo direto das políticas de preservação patrimonial implementadas na cidade, que priorizam o tombamento de edificações excepcionais e de forma isolada? Ou, ainda, seria a falta de espaço nos atuais 
currículos de instituições particulares de ensino de Arquitetura e Urbanismo para a construção de outros olhares em relação à cidade? Coube, então, aos docentes redirecionar os olhares dos alunos. 0 Quadrilátero Central deveria ser percorrido, visto e interpretado como um conjunto, nele sendo percebidos edifícios excepcionais e modestos, maiores e menores, antigos e recentes, tombados ou não.

Foram adotados critérios visuais, de modo a incentivar os alunos a identificarem nessas edificações, passadas despercebidas em seus cotidianos, traços de historicidade. Buscaram-se platibandas, ornamentos de fachada, caixilharias, porões, alpendres, cachorros e outros elementos e materiais construtivos que não fazem mais parte do repertório arquitetônico atual. A princípio, não foram adotados recortes temporais. Tratou-se, portanto, de um processo empírico, considerado necessário sob o ponto de vista pedagógico, para promover um primeiro contato com a área de estudo. Além das edificações com maior integridade, foram incorporadas aquelas descaracterizadas, cujos elementos, por vezes, encontravam-se ocultos por estruturas móveis ou haviam sido parcialmente removidos, e aquelas arruinadas devido ao abandono. Assim, a equipe coletou fotografias e endereços não apenas de edificações, mas também de fragmentos arquitetônicos dispersos na paisagem.

O Quadrilátero Central é composto por 187 quarteirões e foi dividido em 10 subáreas para efeito de organização dos levantamentos. Os grupos, compostos inicialmente por 3 alunos, ficaram responsáveis por fotografar, lote a lote, cada uma dessas subáreas. Com o levantamento fotográfico em mãos, os alunos identificaram, junto com os docentes, 353 edificações de interesse histórico. Posteriormente, cada uma delas foi vetorizada por meio do software AutoCAD $\AA$, com base em imagens aéreas importadas do Google Earth, conformando um mapa único com todas as 353 edificações.

Para o cadastro de cada imóvel, foi elaborada uma ficha em Word, adaptada do modelo utilizado pelo IPHAN para o Inventário Nacional de Referências Culturais vii (INVENTÁRIO, 2000). Os dados preliminares sobre os imóveis foram colhidos nas Folhas de Informação, documentos de consulta pública cedidos pela Secretaria de Planejamento e Gestão Pública da Prefeitura Municipal de Ribeirão Preto. No entanto, nesses documentos havia uma série de campos incompletos ou com dados divergentes das características físicas dos imóveis selecionados viii. Essas lacunas começaram a ser preenchidas quando consultadas as fontes bibliográficas, cartográficas e fotográficas disponíveis no Arquivo Público e Histórico de Ribeirão Preto (APHRP), que também sinalizavam outras frentes de pesquisas.

Até 2018, portanto, os dados consistiam em edificações vetorizadas em AutoCAD®, fotos de fachadas e fichas cadastrais de cada uma das edificações, não vinculados entre si. Com a adoção do SIG, além da integração dos dados cadastrais, foi possível o georreferenciamento das edificações de interesse histórico remanescentes na paisagem, bem como da associação a outras fontes arquivísticasix.

\section{SIG HISTÓRICO DO QUADRILÁTERO CENTRAL DE RIBEIRÃO PRETO}

O QGIS foi o software utilizado na segunda fase do projeto de documentação. Nele, foi criado um projeto para o Quadrilátero Central. Para a confecção do mapa base, foram utilizadas ortofotos da área de 2016. Sobre essa base, foram vetorizadas as edificações de interesse histórico levantadas em campo (Figura 2). Em cada feição gerada, ou seja, em cada polígono de representação de uma edificação, foram inseridos valores nos campos predefinidos, cujo preenchimento esteve condicionado à disponibilidade de informações nas fontes consultadas. 
Figura 2. Edificações cadastradas no Quadrilátero Central em QGIS.

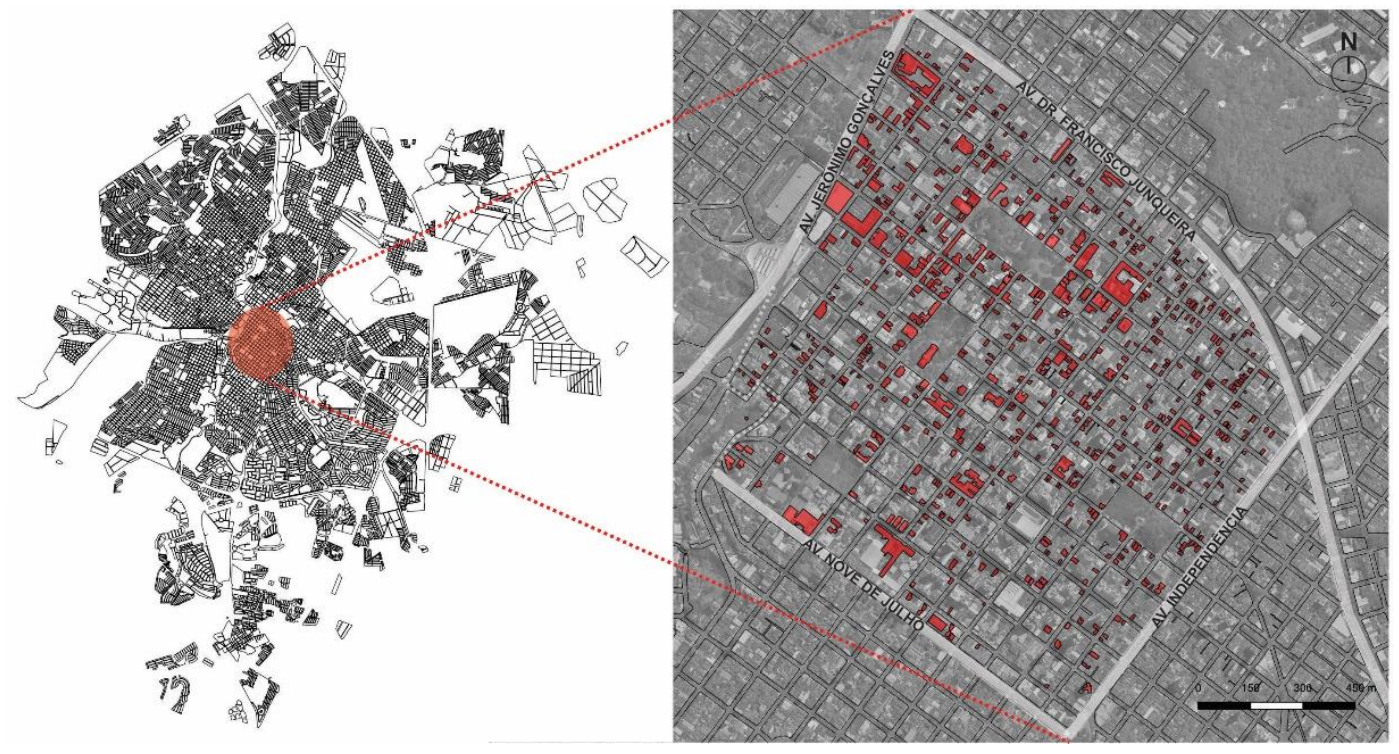

laborado pelos autores sobre imagem aérea do Google Earth, Image @2021 Maxar Technologies.

Como fontes, foram utilizadas as Folhas de Informações das edificações, obtidas junto à Secretaria de Planejamento e Gestão Pública por meio da consulta por endereços; os mapas e os processos administrativos de imóveis disponíveis, respectivamente, na Mapoteca e nas Seções de Obras Públicas e Obras Particulares do APHRP; e as relações de bens tombados no município pelo Conselho de Defesa do Patrimônio Histórico, Arqueológico, Artístico e Turístico (CONDEPHAAT), disponíveis on-line, e pelo Conselho de Preservação do Patrimônio Cultural do Município de Ribeirão Preto (CONPPAC-RP), cedidas aos autores.

Os cadastros da fase anterior do projeto foram revistos e ampliados, chegando-se a um total de 720 edificações, dentre as quais, exemplares datados desde fins do século XIX até o final da década de 1970. Para a localização do imóvel, foram previstos 4 campos na janela de atributos: Logradouro; Número do imóvel; Número antigo (quando existente) e Identificação do bem (denominação oficial, se houver).

Em seguida, constam os campos relativos ao grau de proteção da edificação e aos respectivos números dos processos de tombamento nos âmbitos federal, estadual e ou municipal, quando existentes. Trinta e nove bens do Quadrilátero Central são tombados, dentre os quais trinta e três são edificações, de propriedade pública e particular.

Com base nas Folhas de Informações dos imóveis, foram inseridos dados referentes ao Ano do projeto, Ano de construção, Autor do projeto e o Responsável técnico (Figura 3). Uma vez que nem todas as Folhas contêm essas informações, o preenchimento desses campos está sendo complementado com os dados obtidos diretamente dos projetos de arquitetura disponíveis na Seção Obras Particulares do APHRP. Além dos documentos, em alguns imóveis, as próprias platibandas informam o ano de construção.

A partir das Folhas de Informações e dos projetos de arquitetura, será possível datar ou, ao menos, estimar a ocorrência de reformas nos imóveis. Para tanto, foi criado um outro campo, organizado de acordo com décadas, chamado Reformas - Décadas. 


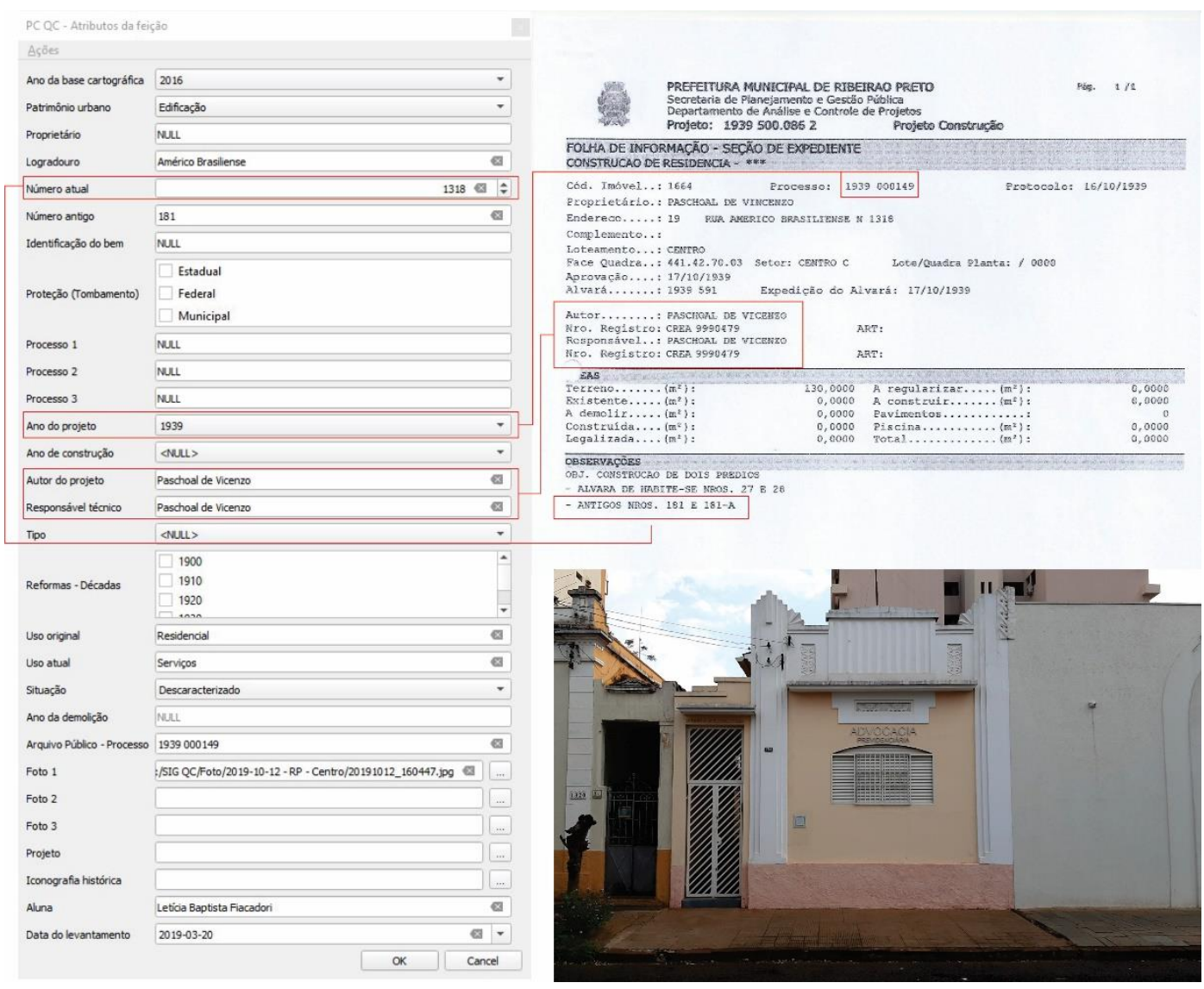

Na sequência, estão os campos para inserção das fotografias produzidas nos levantamentos de campo. A análise desse conjunto de fotografias apontou para a forte presença de tipos arquitetônicos, reproduzidos em todo o Quadrilátero Central e diretamente vinculados aos usos originalmente previstos em projeto. A leitura desses tipos recupera a teoria muratoriana, na medida em que revela uma produção voltada para as classes mais populares, pautada não na erudição da prática arquitetônica, mas na perpetuação de técnicas construtivas e soluções espaciais nem sempre aderentes a referenciais estilísticos. Uma segunda hipótese, ainda em estudo, é a de que esses tipos estavam diretamente ligados às primeiras tentativas de seriação de projetos voltadas para o atendimento de um mercado da construção civil em fértil crescimento até a crise de 1929 e após a Segunda Guerra Mundial.

Casas térreas sobre porão, casas tipo chalé, sobrados com jardim frontal, casas com alpendre de entrada lateral e sobrados de esquina com uso misto são alguns dentre os tipos identificados até o momento. Desse modo, mesmo quando os projetos não forem localizados, poderão ser identificados padrões nos programas e na ocupação dos lotes e possíveis autores, a partir de análises comparativas (Figura 4).
Figura 3. Cadastro de imóvel situado à Rua Américo Brasiliense 1318, com base na respectiva Folha de Informação.

\section{Fonte:}

Secretaria de Planejamento e Gestão Pública; Foto de Gustavo Zeoti, 2019. 
Figura 4. Exemplos de tipo arquitetônico comercial de
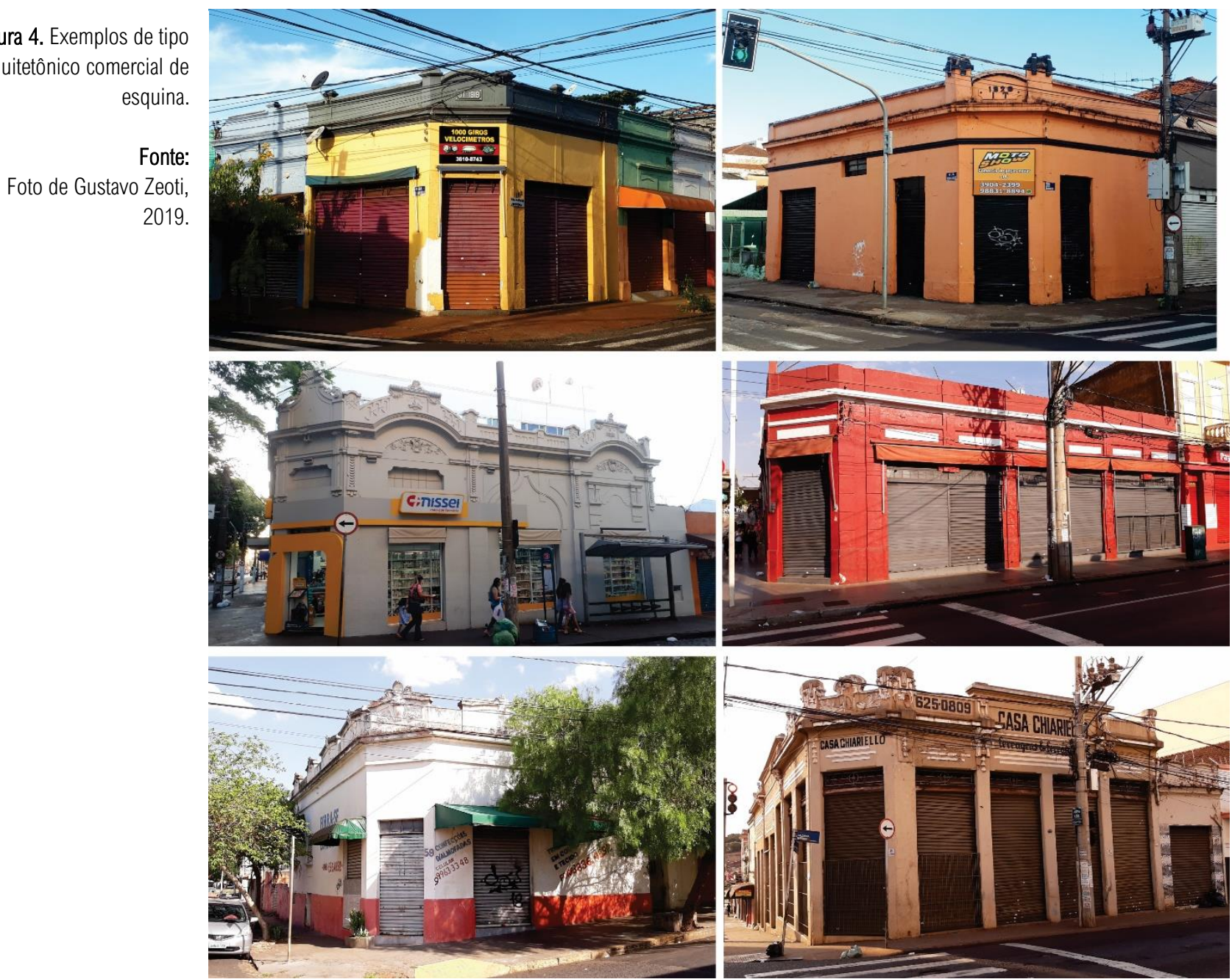

Também foram inseridos campos para identificação dos usos original e atual. Calil Júnior (2003) afirma que entre 1940 e 1960 aconteceram mudanças nos processos de expansão e setorização do Centro. A partir da década de 1960 se inicia o processo de verticalização, sobretudo para fins residenciais. Ainda assim, há um número considerável de edificações que mantiveram o uso original residencial ou misto. Desde 2016, quando iniciado o projeto no âmbito do Escritório Modelo, diversas edificações foram demolidas, sendo que uma delas estava sob regime de tombamento provisório e outra na envoltória do Grupo Escolar Fábio Barreto, tombado pelo CONDEPHAAT. Para o registro do estado de conservação do imóvel, foi inserido o campo Situação, um menu desdobrável, com os seguintes campos: Arruinado, Conservado, Demolido e Descaracterizado. No caso de demolição, há um campo para a inserção do ano em que ela aconteceu.

Por fim, estão estruturados os campos para inserção do conteúdo documental. 0 primeiro serve para a inserção do número do processo do imóvelx. Todos os projetos para o Quadrilátero Central estão sendo digitalizados com o uso de um escaner de mão, exceto aqueles que estão em condições muito frágeis para o manuseio. Esses estão sendo apenas catalogados. Os demais, em condição de manuseio, estão sendo salvos como arquivos de imagem e inseridos no campo Projeto ${ }^{\mathrm{xi}}$. 
0 APHRP possui ainda um rico acervo fotográfico, do qual aproximadamente 400 fotografias são de ruas, praças e edificações situadas no Quadrilátero Central. A maioria das fotos enfatiza as grandes edificações erguidas até 1940, como a Catedral, o Teatro Pedro II, o Edifício Diederichsen e o Palácio Rio Branco. No entanto, no plano de fundo de muitas delas, é possível identificar as arquiteturas menores. Além dessas fotos, há ainda coleções de particulares, como a da Casa da Memória Italiana, que poderá ser somada ao banco de dados uma vez obtida a autorização para reprodução das imagens. Para inserção dessas imagens, foi criado o campo Iconografia histórica (Figura 5), no qual foram inseridas as fotografias dos respectivos imóveis.

Além dos campos já previstos, outros podem ser inseridos de forma dinâmica, adequando-se aos objetivos dos usuários. 0 material bruto pode ser de interesse tanto para pesquisadores quanto para gestores públicos. Ademais, os dados sistematizados relativos ao patrimônio urbano também podem ser uma estratégia de educação patrimonial, que vai além dos grandes monumentos tombados.

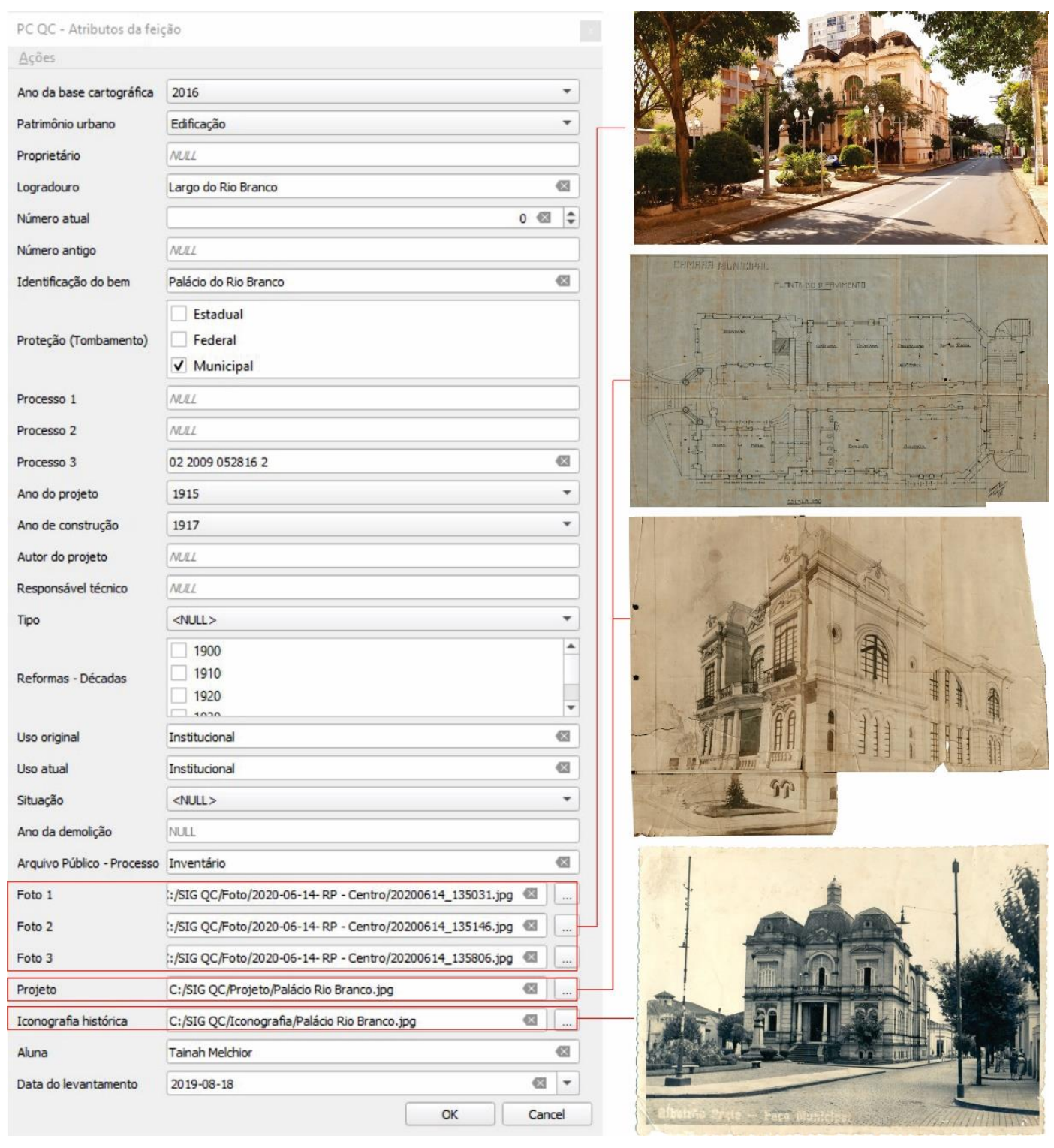

Figura 5 Cadastro do Palácio Rio Branco, sede da Prefeitura Municipal de Ribeirão Preto.

Fonte:

Foto (acima): Gustavo Zeoti, 2020; Desenhos e foto (abaixo): Arquivo Público e Histórico de Ribeirão Preto (APHRP). 


\section{CONSIDERAÇÕES FINAIS}

Com os resultados obtidos até o momento, constatou-se que ainda subsistem centenas de exemplares de interesse histórico - total de 720 -, mesmo diante de tantas demolições, abandonos e descaracterizações de edificações situadas no Quadrilátero Central. Esse expressivo número de edificações cadastradas reforça a importância histórica da área, na qual as arquiteturas menores ocupam a maior parte da malha urbana e conferem a ambiência histórica da área. Ainda assim, as estratégias de proteção patrimonial geralmente ficam restritas ao tombamento de edificações monumentais e isoladas.

Não se trata apenas de uma área onde se concentra a maior parte dos bens tombados do município, mas sim de uma paisagem histórica urbana, essencialmente heterogênea e que retrata parte do processo de transformação da cidade. Nessa direção, a esse cadastro poderiam ser adicionados outros dados relativos aos demais elementos constitutivos da paisagem urbana, tais como mobiliário urbano, espaços livres, vegetação, e os próprios valores e significados culturais a eles imbricados. 0 cadastro das arquiteturas menores é, portanto, um primeiro passo para o reconhecimento da paisagem histórica urbana.

0 uso do SIG possibilitou, além do armazenamento e espacialização de grande volume de dados acerca de bens materiais, a realização de classificações, cruzamentos de dados e outras formas de processamento. A criação desse sistema abre a possibilidade de aplicação a outros recortes territoriais, tanto do próprio município quanto de outros. Há, portanto, potencial para sua replicabilidade.

Ribeirão Preto dispõe de sistemas de informações que abrangem dados de diversos órgãos da administração pública municipal. No entanto, os dados da Secretaria de Cultura, responsável pela proteção do patrimônio cultural, não se encontram sistematizados. A disponibilização para os órgãos da administração pública do sistema de cadastro aqui apresentado, bem como a divulgação dessa experiência, pode colaborar para o desenvolvimento de políticas públicas de preservação do patrimônio arquitetônico em parceria com universidades. Isto poderia não apenas facilitar e enriquecer o planejamento e a gestão do patrimônio, como também ampliar as escalas de preservação, para além das edificações grandiosas e isoladas.

\section{Referências Bibliográficas}

ARONOFF, S. Geographic Information Systems: A Management Perspective. Otawa: WDL Publications, 1991.

ARRUDA, A. K. T.; AMORIM, A. L. de. Heritage Information System: tecnologias digitais aplicadas ao planejamento e gestão de intervenções urbanas: um modelo conceitual. In: CONGRESO DE LA SOCIEDAD IBEROAMERICANA DE GRÁFICA DIGITAL, 14., 2010, Bogotá. SIGRADI 2010. Bogotá: Uniandes, 2010. p. 399-402. Disponível em: http://papers.cumincad.org/data/works/att/sigradi2010_399.content.pdf. Acesso em: 8 fev. 2021.

BRASIL. [Constituição (1988)]. Constituição da República Federativa do Brasil de 1988. Brasília, DF: Presidência da República, [2020]. Disponível em: http://www.planalto.gov.br/ccivil_03/Constituicao/Constituiçao.htm. Acesso em: 9 fev. 2021.

BUENO, B. P. S. Arqueologia da paisagem urbana. SIG Histórico e Mercado imobiliário. Reconstituição do Centro Histórico de São Paulo (1809-1942). In: SEMINÁRIO DE HISTÓRIA DA CIDADE E DO 
URBANISMO, 14., 2016, São Carlos. Anais do XIV Seminário de História da Cidade e do Urbanismo Cidade, Arquitetura e Urbanismo: Visões e Revisões do Século XX. São Carlos: IAU-USP, 2016. p. 442455. Disponível em: https://www.iau.usp.br/shcu2016/anais/wp-content/uploads/pdfs/44.pdf. Acesso em: 9 fev. 2021.

BURKE, P. A Revolução Francesa da historiografia: a Escola dos Annales 1929-1989. 2 ed. São Paulo: Editora Universidade Estadual Paulista, 1992.

CABRAL, R. C. A noção de "ambiente" em Gustavo Giovannoni e as leis de tutela do patrimônio cultural na Itália. 2013. Tese (Doutorado em Arquitetura e Urbanismo) - Instituto de Arquitetura e Urbanismo, Universidade de São Paulo, São Carlos, 2013. Disponível em:

https://teses.usp.br/teses/disponiveis/102/102132/tde-25062014-093621/pt-br.php. Acesso em: 9 fev. 2021.

CALIL JUNIOR, O. O Centro de Ribeirão Preto: os processos de expansão e setorização. 2003. Dissertação (Mestrado em Arquitetura). EESC - USP, São Carlos, 2003.

CANIGGIA, G.; MAFFEI, G. L. Tipologia de la edificación. Estructura del espacio antropico. Tradução: Margarita Garda Galán. Madrid: Celeste Ediciones, 1995.

CERVELATTI, P. L.; SCANNAVINI, R. Bolonia. Politica y Metodologia de la Restauración de Centros Históricos. Barcelona: Editorial Gustavo Gili, 1976.

CHOAY, F. A alegoria do patrimônio. Tradução: Luciano Vieira Machado. 3 ed. São Paulo: Estação Liberdade, UNESP, 2006.

CONSELHO DA EUROPA. Congresso do Patrimônio Arquitetônico Europeu. Declaração de Amsterdã. Amsterdã: Conselho da Europa, 1975. Disponível em: http://portal.iphan.gov.br/uploads/ckfinder/arquivos/Declaracao\%20de\%20Amsterda\%CC\%83\%20 1975.pdf. Acesso em: 12 abr. 2020.

GAUTHIEZ, B. Lyon, das fontes escritas ao SIG histórico - método e exemplos de aplicação. Revista do Instituto de Estudos Brasileiros, São Paulo, n. 64, p. 21-50, ago. 2016. Disponível em: https://www.revistas.usp.br/rieb/article/view/119563. Acesso em: 20 dez. 2020.

GIOVANNONI, G. Textos escolhidos. Tradução: Beatriz Mugayar Kühl. Cotia: Ateliê Editorial, 2013.

ICOMOS. Carta de Veneza. Carta para a Conservação e Restauração de Monumentos e Sítios (1964). Veneza: ICOMOS, 1964. Disponível em:

http://portal.iphan.gov.br/uploads/ckfinder/arquivos/Carta\%20de\%20Veneza\%201964.pdf. Acesso em: 29 fev. 2020.

INVENTÁRIO Nacional de Referências Culturais: manual de aplicação. Brasília: Instituto do Patrimônio Histórico e Artístico Nacional, 2000.2 Disponível em: http://portal.iphan.gov.br/uploads/ckfinder/arquivos/Manual_do_INRC.pdf. Acesso em: 9 fev. 2021.

MOTTA, L. Patrimônio Urbano e Memória Social: práticas discursivas e seletivas de preservação cultural - 1975 a 1990. 2000. Dissertação (Mestrado em Memória Social e Documento) - Programa de Pós-Graduação em Memória Social, Universidade do Rio de Janeiro, Rio de Janeiro, 2000. Disponível em: http://www.repositorio-bc.unirio.br:8080/xmlui/handle/unirio/12610. Acesso em: 13 jun. 2020. 
Ana Teresa Cirigliano Villela anacirigliano.arquitetura@gmail.

$\underline{\mathrm{com}}$

Gustavo Nogueira Zeoti

gustavozeoti@gmail.com

PANERAI, P. Análise Urbana. Tradução: Francisco Leitão. Brasília: Editora Universidade de Brasília, 2006.

PREFEITURA MUNICIPAL DE RIBEIRÃO PRETO. Lei Complementar no 2.157, de 8 de janeiro de 2007. Dispõe sobre o Parcelamento, Uso e Ocupação do Solo no Município de Ribeirão Preto. Ribeirão Preto: Prefeitura Municipal de Ribeirão Preto, 2007. Disponível em:

https://www.ribeiraopreto.sp.gov.br/legislacao-municipal/pesquisa.xhtml?lei=21377. Acesso em: 17 mar. 2020.

RIEGL, A. O culto moderno dos monumentos: a sua essência e a sua origem. Tradução: Wener R. Davidsohn; Anat Fabel. São Paulo: Perspectiva, 2014.

RUBINO, S. O mapa do Brasil passado. Revista do Patrimônio Histórico e Artístico Nacional, Rio de Janeiro, n. 24, p. 96-105, 1996. Disponível em:

http://portal.iphan.gov.br/uploads/publicacao/RevPat24.pdf. Acesso em: 7 jun. 2020.

TOSCO, Carlo. Il paesaggio come storia. Bologna: Società Editriceil Mulino, 2017. E-book.

UNESCO. Recomendação sobre a Paisagem Histórica Urbana. Paris: UNESCO, 2011. Disponível em: https://www.unescoportugal.mne.pt/images/cultura/recomendacao_sobre_a_paisagem_historica _urbana_unesco_2011.pdf. Acesso em: 25 maio 2020.

WAISMAN, M. O interior da História: historiografia arquitetônica para uso de latino-americanos. Tradução: Anita Di Marco. São Paulo: Perspectiva, 2013.

WEIMER, G. Arquitetura popular brasileira. São Paulo: Martins Fontes, 2005.

\section{Notas}

\footnotetext{
'Área circunscrita pelas avenidas Francisco Junqueira, Independência, Jerônimo Gonçalves e Nove de Julho, instituída por meio da Lei Complementar no 2.157 de 31 de janeiro 2007 (PREFEITURA MUNICIPAL DE RIBEIRÃO PRETO, 2007).

ii É referência o SIG histórico de Lyon, coordenado por Bernard Gauthiez com o objetivo de estudar as transformações materiais da paisagem e, em seguida, o seu espaço social, a partir do georreferenciamento e interpretação crítica das licenças de construção emitidas desde 1617 (GAUTHIEZ, 2016).

iii A exemplo da francesa "Societé Nationale de Protection des Paysages", de 1901, da inglesa "National Trust for Places of Historic Interest and Natural Beauty", de 1904, e da alemã "Bund Deutscher Hiematschutz", de 1904 (TOSCO, 2017).

iv Os mestres portugueses de formação artesanal, responsáveis pela produção arquitetônica do ciclo do ouro mineiro, "[...] foram qualificados como arquitetos eruditos na medida em que só passaram a ser valorizadas suas obras de destaque, em especial as construções religiosas. Quando isso não era possível, como no caso do mulato Antônio Francisco Lisboa, o Aleijadinho, usou-se o expediente de contornar o problema de sua formação deficiente atribuindo-lhe qualificativos de excepcionalidade, e ele passou a ser festejado como artista máximo do período por sua pretensa genialidade." (WEIMER, 2005, p. XXXVII).

" Destaca-se a reconstrução de Bolonha, na Itália. Ver mais em: CERVELATTI, P. L.; SCANNAVINI, R. Bolonia. Politica y Metodologia de la Restauración de Centros Históricos. Barcelona: Editorial Gustavo Gili, 1976.
} 
vi "Este contexto mais abrangente inclui [...] a topografia, a geomorfologia, a hidrologia e as características naturais do local, o ambiente construído, tanto histórico como contemporâneo, as suas infraestruturas à superfície ou subterrâneas, os espaços livres e os jardins, os padrões de ocupação do solo e organização espacial, as percepções e relações visuais, assim como todos os outros elementos da estrutura urbana. Inclui, igualmente, as práticas e os valores sociais e culturais, os processos económicos e as dimensões imateriais do património, enquanto vetores de diversidade e identidade." (UNESCO, 2011, p. 4).

vii Como não foram feitos levantamentos internos, as informações da ficha modelo foram sintetizadas.

viii Essa incompatibilidade se deu sobretudo devido às mudanças de numeração dos imóveis. 0 sistema de numeração atual foi adotado em 1948. A partir de então, o número de cada prédio passaria a corresponder, aproximadamente, à distância em metros, medida pelo eixo da via, desde a sua origem até o meio da soleira, sendo par à direita e ímpar à esquerda (PREFEITURA MUNICIPAL DE RIBEIRÃO PRETO, 1948).

ix Conjunto de documentos bibliográficos, fotográficos e cartográficos obtidas em arquivos públicos e privados.

* Os processos até 1979 encontram-se disponíveis no APHRP. Até a década de 1930, eles contêm apenas as pranchas de projeto, com raras exceções. Já a partir da década de 1930, é possível encontrar, além das pranchas de projeto, os pedidos e os memoriais descritivos, elaborados e assinados pelos autores do projeto e/ou construtores.

${ }^{x i}$ Todos os projetos de arquitetura de imóveis localizados na região central, inclusive aqueles relativos a imóveis já demolidos, estão sendo digitalizados no âmbito da tese "Arqueologia da Paisagem Urbana: o processo de (trans)formação do Quadrilátero Central de Ribeirão Preto (SP)". 